\title{
Fatigue and workload among Danish fishermen
}

\author{
Line Nørgaard Remmen ${ }^{1}$, Kimmo Herttua ${ }^{2}$, Jørgen Riss-Jepsen ${ }^{3}$, Gabriele Berg-Beckhoff ${ }^{1}$ \\ ${ }^{1}$ Department of Public Health - Unit for Health Promotion, University of Southern Denmark, Esbjerg, Denmark \\ ${ }^{2}$ Centre of Maritime Health and Society, University of Southern Denmark, Esbjerg, Denmark \\ ${ }^{3}$ Department of Occupational Medicine, Hospital of Southwestern Denmark, Denmark
}

\begin{abstract}
Background: Fishery is a hazardous occupation and fatigue may contribute to the observed risks. This study aims to investigate the association between workload and fatigue among Danish fishermen.

Materials and methods: The cross-sectional survey of demographic characteristics and self-reported exposure and health data was performed on a random sample of 270 active fishermen. We applied the validated Multidimensional Fatigue Inventory (MFI-20) to assess the degrees of the different dimensions of perceived fatigue. We estimated physical workload using questions regarding the frequency of seven physical work activities and analysed the association between fatigue and workload using multiple linear regressions.

Results: The mean fatigue scores were 9.18 (SD 3.58) for general fatigue, 9.05 (SD 3.36) for physical fatigue, 7.57 (SD 3.03) for reduced activity and 7.16 (SD 3.07) for mental fatigue. Highest levels of fatigue were observed among fishermen at Danish seiners (mean 10.21), and fatigue scores decreased with more days at sea. However, none of these results were significant. Adjusted analyses showed that physical workload was significantly related to general fatigue $(\beta=0.20,95 \% \mathrm{Cl}: 0.12-0.28)$, physical fatigue $(\beta=0.10,95 \% \mathrm{Cl}: 0.04-0.16)$ and mental fatigue $(\beta=0.09,95 \% \mathrm{Cl}: 0.01-0.16)$. Reduced activity was unrelated to work exposures.

Conclusions: General fatigue was the dominant fatigue dimension among Danish fishermen and it is mostly associated with physical workload. Physical workload was additionally significantly associated to the levels of physical and mental fatigue. Fishermen had a lower average score for all fatigue dimensions compared to those seen in general Danish working population. Prospective studies are required to assess whether the identified associations are causal.
\end{abstract}

(Int Marit Health 2017; 68, 4: 252-259)

Key words: commercial fishing, fatigue dimensions, work conditions, Multidimensional Fatigue Inventory, MFI-20, occupational health

\section{INTRODUCTION}

Commercial fishing is often regarded as a very hard occupation and it is consistently found to be one of the most dangerous occupations with a high rate of severe or fatal occupational accidents and hospitalisation due to different diseases in Denmark [1-3] and worldwide [4-8]. However, many safety measures and ergonomic improvements have been developed and applied in Danish occupational fishing in recent years, resulting in a positive development of the physical work environment and a significant reduction of occupational accidents [9]. Still, commercial fishing involves high workloads with frequent manual handling and use of heavy equipment in a wet, slippery and moving environment [10].

Susceptibility to poor health and accidents among fishermen can be explained by a combination of individual and environmental factors. These risk factors comprise constant movements and vibrations of the vessels, shifting weather conditions and temperatures, long working hours and shift work - factors that may all affect the fishermen's work postures, performance, perceived workload, rest and sleep [11, 12]. These factors may in turn lead to fatigue, a condition that can have a negative effect on fishermen's health and safety. Fatigue is defined as a multidimensional condition causing

Msc. Line Nørgaard Remmen, Institute of Public Health, University of Southern Denmark, Niels Bohrs Vej 9, 6700 Esbjerg, Denmark, e-mail: Iremmen@health.sdu.dk 


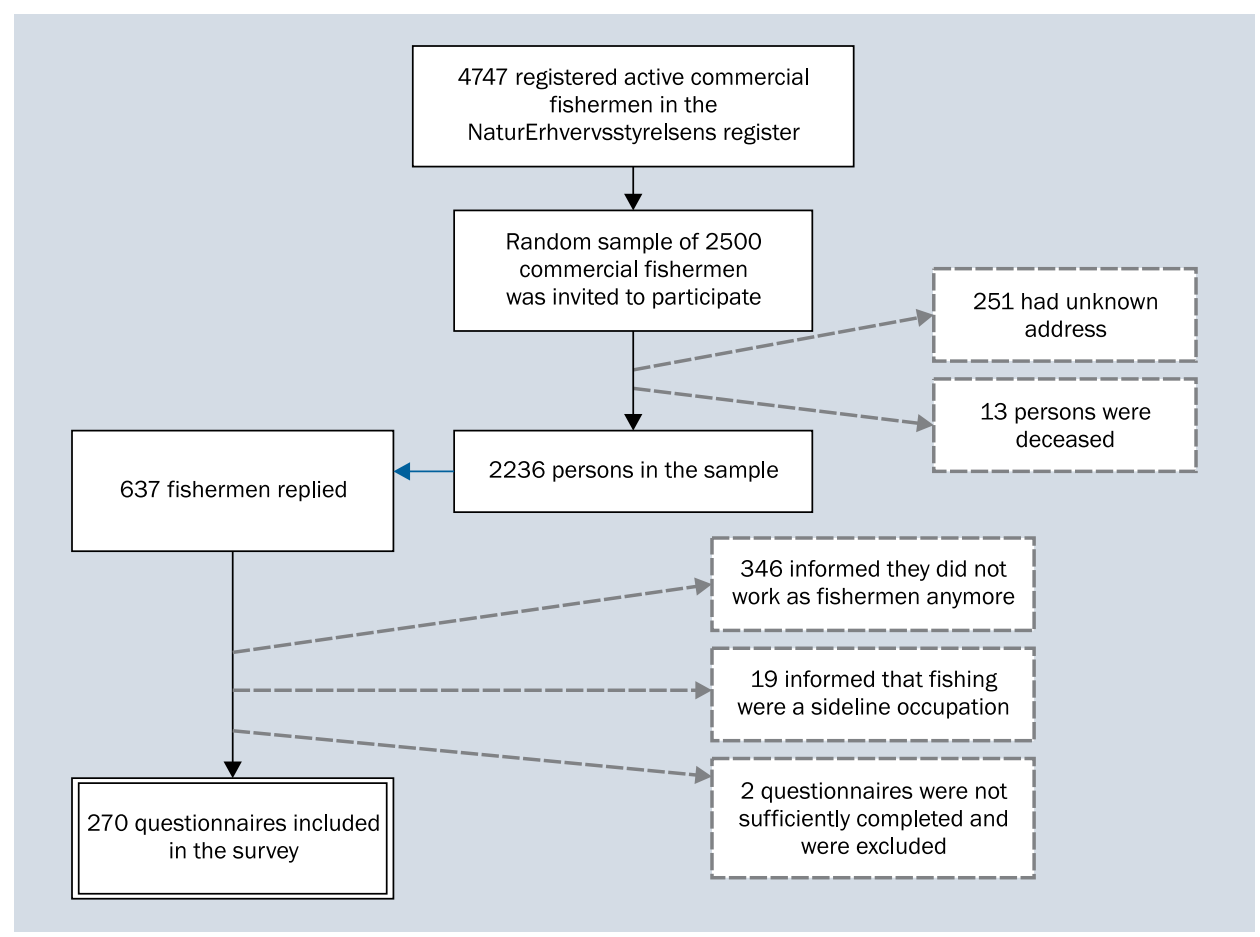

Figure 1. Flowchart of study population

reduction in an individual's physical and/or mental capability. The resulting physical, mental and emotional exertion may impair all physical abilities such as strength, reaction time, balance and decision-making [13]. Fatigue reduces awareness and it is therefore especially risky among fishermen because of their unique working environment $[12,14]$.

Few studies have investigated fishermen's fatigue. One study has assessed the association between sleep and fatigue [15], while other studies took several additional risk factors into consideration such as working hours and number of voyages [12, 14, 16]. Fatigue in male fishermen was shown to be frequently on a level that affected their work [14]. We are not aware of studies that have investigated the association between physical workload and the degree of fatigue employing a multidimensional scale of fatigue. Consequently, the absence of such evidence on fatigue in fishermen stresses the need for further research aiming to achieve better understanding of the relation between fatigue and fishermen's health and safety at sea. Such relation may in turn lead to actions that can reduce the adverse impact of fatigue.

The aim of this study is to investigate the association between perceived multidimensional fatigue and physical workload among Danish fishermen.

\section{MATERIALS AND METHODS}

\section{STUDY DESIGN}

A cross-sectional study of self-reported exposure and health data among Danish fishermen was conducted be- tween February and April 2015 as part of a project funded by the European Fisheries Fund (J. no. 3301013-k-0264). Out of 2.236 randomly selected active Danish fishermen registered by The Danish AgriFish Agency (NaturErhvervsstyrelsen) who were invited to participate, 637 replied resulting in a response rate of $28 \% .367$ respondents were excluded due to their current employment status: 346 had retired, 19 were only fishing as a sideline occupation, and two fishermen were excluded due to inadequate questionnaire responses. 270 fishermen were included in the final analysis (Fig. 1).

The questionnaire contained questions about demographic factors, self-reported occupational and general health data, such as perceived workload, musculoskeletal pain and fatigue [17]. The applied procedures were in accordance with the STROBE statement [18]. Informed consent was obtained from all participants and the study was approved by the Danish data protection Agency (J. no. 2014-41-3245).

\section{MULTIDIMENSIONAL FATIGUE INVENTORY (MFI-20)}

The levels of fatigue among the fishermen were assessed using the validated Multidimensional Fatigue Inventory (MFI-20), which consists of 20 items for investigation of fatigue in five different dimensions: general fatigue, physical fatigue, reduced activity, reduced motivation, and mental fatigue. General fatigue includes a general statement concerning a person's experience of tiredness. Physical fatigue 
refers to the physical experience relating to the feeling of tiredness. The level of activity and the motivation to start any activity are investigated with the scales of reduced activity and reduced motivation, respectively. Finally, mental fatigue covers the feeling of cognitive symptoms such as having concentration problems. Each dimension contained four items for which the fishermen had to indicate on a five-point scale how the particular statement suited their experience. An equal number of items were worded in a positive and a negative way to counteract for response tendencies. A score of four indicated no presence of fatigue, while a score of 20 indicated the highest level of fatigue [19-21]. A conditional missing imputation was conducted if any answer in these scores was missing. To impute the missing values, the mean value of the remaining questions of the related person was calculated. The final fatigue data for analysis included 261 fishermen (excluded due many missing answers about fatigue $=9$ ). Cronbach's alpha scores were applied as a measure for internal consistency (Table 1) [22]. The absence of internal consistency in one of the MFI-20 fatigue dimensions, namely reduced motivation, resulted in its exclusion.

\section{PHYSICAL WORKLOAD}

Estimation of the physical workload was based on questionnaire information about seven work postures originating from the FINALE project [23]: standing, pushing and pulling, carrying and lifting, lifting object with hands above the shoulders, with the back bending forwards, twisting and bending, and heavy repeated work with fingers. The degrees of physical workload were evaluated using a six-point scale. For analysis, an additional overall workload-score was developed by summing up the scores from all seven items resulting in a score ranging from 7 to 42 . Conditional missing imputation was conducted when up to two questions were missing. Cronbach's alpha was 0.81, which indicates a good internal consistency for the scale [22].

\section{CO-VARIABLES}

Work-related differences between skipper and deckhands were investigated. Respondents who did not inform about their occupational group on board $(n=19)$ were included as deckhands because the working tasks of these are not as clearly defined than those of the skippers. The following types of vessels were recorded: trawlers, Danish seiners, netters, liners, potters, and others (including missing values). Days at sea were categorised as "one day", "two to seven days" and "more than one week", and information about duration of work (years) and fishing as sideline occupation (yes or no) was additionally investigated. Demographic variables included the fishermen's age and education categorised into basic education, skilled worker
Table 1 Inclusion and exclusion of fatigue dimensions in study due to tested internal consistency of the five fatigue dimensions in Multidimensional Fatigue Inventory (MFI-20) in Danish fishermen $2015(n=261)$

\begin{tabular}{lll}
\hline & $\begin{array}{l}\text { Cronbach's } \\
\text { alpha }\end{array}$ & $\begin{array}{l}\text { Inclusion/ } \\
\text { /Exclusion }\end{array}$ \\
\hline General fatigue & 0.73 & Included \\
Physical fatigue & 0.59 & Included \\
Reduced activity & 0.65 & Included \\
Reduced motivation & 0.28 & Excluded \\
Mental fatigue & 0.72 & Included
\end{tabular}

and advanced education. Body mass index was calculated $\left(\mathrm{kg} / \mathrm{m}^{2}\right)$ from weight and height. Fishermen's sleep was investigated with two items; sleep during a fishing voyage and sleep at home. Furthermore, perceived level of pain and scores for physical resources (score summed up by data on physical fitness, strength, endurance, mobility and balance) were included.

\section{STATISTICAL ANALYSIS}

The associations between fishermen's work characteristics and workload and general fatigue, physical fatigue, reduced activity and mental fatigue were investigated using simple one way ANOVA and multiple linear regressions (Stata ver. 14.0). In the multiple linear regression both confounding and interaction effects were tested. Relevant confounders were age, education, side-line occupation, physical resources, sleep at voyage, professional group, type of vessel, and days at sea. An analysis of the interaction [24] between workload, age and the degree of fatigue demonstrated the absence of any significant interaction (general fatigue $p=0.70$, physical fatigue $p=0.11$, reduced activity $p=0.17$ and mental fatigue $p=0.23$ ). Consequently, stratification by age groups was not required. Model assumptions were graphically tested and fulfilled.

\section{RESULTS}

All 270 Danish fishermen who completed the questionnaire were males. Their mean age was 53 years (SD 13.5), ranging from 17 to 80 years. The average duration of working as a commercial fisherman was 31 years. $64 \%$ of the fishermen were skippers and $44 \%$ worked on trawlers (Table 2). Almost half of the participants worked one day at a time, and a fifth worked continuously more than seven days at a time. $76 \%$ of the fishermen were obese or overweight, and $25 \%$ had a sideline occupation such as beekeeper or craftsman.

The prevalence of fatigue was investigated through data from MFI-20, with scoring options ranging from 4 to 20 , four 
Table 2. Socio-demographics and work characteristics of the Danish fishermen in the cross sectional survey in $2015(n=270)$

\begin{tabular}{|c|c|c|}
\hline & Mean & Number (\%) \\
\hline \multicolumn{3}{|l|}{ Occupational group } \\
\hline Skipper & & $167(63.59 \%)$ \\
\hline Deckhands $^{a}$ & & $103(38.15 \%)$ \\
\hline Age [years] & 53.12 & \\
\hline$\leq 29$ & & $20(7.41 \%)$ \\
\hline $30-39$ & & $22(8.15 \%)$ \\
\hline $40-49$ & & 54 (20.00\%) \\
\hline $50-59$ & & $82(30.37 \%)$ \\
\hline$\geq 60$ & & $90(33.33 \%)$ \\
\hline Missings & & $2(0.74 \%)$ \\
\hline \multicolumn{3}{|l|}{ Vessel type } \\
\hline Trawler & & $118(43.70 \%)$ \\
\hline Danish seiners & & $14(5.19 \%)$ \\
\hline Netters and lines & & 75 (27.78\%) \\
\hline Potters & & $28(10.37 \%)$ \\
\hline Other type ${ }^{b}$ & & 35 (12.96\%) \\
\hline \multicolumn{3}{|l|}{ Days/weeks of fishing } \\
\hline 1 day & & 124 (45.93\%) \\
\hline $1-7$ days & & 90 (34.07\%) \\
\hline More than 7 days & & 44 (16.30\%) \\
\hline Missings & & $12(4.44 \%)$ \\
\hline \multicolumn{3}{|l|}{ Sideline occupation } \\
\hline No & & $195(77.22 \%)$ \\
\hline Yes & & $62(22.96 \%)$ \\
\hline Missings & & $13(4.81 \%)$ \\
\hline \multicolumn{3}{|l|}{ Level of education } \\
\hline Basic education & & $137(50.74 \%)$ \\
\hline Skilled worker & & 63 (23.33\%) \\
\hline Advanced education & & $50(18.52 \%)$ \\
\hline Missings & & $8(2.96 \%)$ \\
\hline \multicolumn{3}{|l|}{ Sleep at voyage } \\
\hline$>6$ hours & & $161(67.08 \%)$ \\
\hline$<6$ hours & & 86 (31.85\%) \\
\hline Missings & & $23(9.58 \%)$ \\
\hline Physical resource score & 33.76 & \\
\hline Missings & & 4 (1.48\%) \\
\hline
\end{tabular}

meaning a total absence of fatigue and 20 meaning the highest degree of fatigue possible. The fishermen's average degree of fatigue was below 10 in all four dimensions of fatigue (Table 3). The average fatigue scores were 9.18 (SD 3.58) for general fatigue, 9.05 (SD 3.36) for physical fatigue, 7.57 (SD 3.03) for reduced activity and 7.16 (SD 3.07) for mental fatigue. The fatigue scores of fishermen related to their work are also presented in Table 3. The average fatigue scores do not differ in between skippers and deckhands. However, differences can be observed according to the vessel type: fishermen sailing with Danish seiners had higher average fatigue scores whereas fishermen on trawlers had lower ones. Furthermore, we identified a trend relating to the temporal extension of fishing. The highest average fatigue scores were found in fishermen who were fishing one day at a time and the lowest when fishing journeys lasted more than seven days at a time. However, none of these differences reached significant levels.

The physical workload of the fishermen ranged from 7 to 42 with an average of 24.22 (SD 5.98). The descriptive analysis showed a tendency of the highest degree of fatigue for fishermen who worked more than half of the time in the seven investigated working positions.

The adjusted multiple linear regression analysis showed that the score for physical workload was significantly related to general fatigue $(\beta=0.20,95 \% \mathrm{Cl}$ : $0.12-0.28)$, physical fatigue $(\beta=0.10,95 \% \mathrm{Cl}: 0.04-0.16)$ and mental fatigue $(\beta=0.09,95 \% \mathrm{Cl}: 0.01-0.16)$, but not to reduced activity (Table 4). Age, education, side line occupation, physical resources, professional group type of vessel and days at sea were considered as confounder. These results indicate that general fatigue was associated with the fishermen's physical workload but higher physical workload was also significantly associated with higher scores in physical and mental fatigue.

\section{DISCUSSION}

This cross-sectional study of fatigue in Danish fishermen showed that general fatigue had the highest mean score of all fatigue dimensions. They were found to be lower in average than scores in two cross-sectional studies about fatigue in the general Danish population [19, 21]. Direct comparison is feasible as the same questionnaire (MFI-20) was used in these two surveys. In the cross-sectional study about fatigue in the Danish midlife population, higher mean scores of the fatigue dimensions were; general fatigue 9.6, physical fatigue 9.1, reduced activity 7.9 and mental fatigue 7.7 [19] while the fishermen's fatigue scores in the current study was 9.2, 9.1, 7.6 , and 7.2, respectively. Given the descriptions of commercial fishing as being of a particularly physically strenuous nature [10, 12] and the found positive association between work load and fatigue, the slightly lower fatigue scores of Danish fishermen compared to the Danish population is a surprising finding.

The differences in fatigue score seen in different vessel types and days out at sea may reflect automation in the in- 
Table 3. Fatigue and fishermen's work characteristics $2015(n=261)$

\begin{tabular}{|c|c|c|c|c|c|c|c|c|}
\hline & \multicolumn{2}{|c|}{ General fatigue } & \multicolumn{2}{|c|}{ Physical fatigue } & \multicolumn{2}{|c|}{ Reduced activity } & \multicolumn{2}{|c|}{ Mental fatigue } \\
\hline & Mean & (SD) & Mean & (SD) & Mean & (SD) & Mean & (SD) \\
\hline All & 9.18 & $(3.58)$ & 9.05 & (3.36) & 7.57 & (3.03) & 7.16 & $(3.07)$ \\
\hline \multicolumn{9}{|l|}{ Occupational group } \\
\hline Skipper & 9.17 & $(0.28)$ & 9.08 & $(0.27)$ & 7.44 & $(0.24)$ & 7.19 & $(0.24)$ \\
\hline Deckhands $^{a}$ & 9.19 & $(0.37)$ & 9.00 & $(0.33)$ & 7.78 & $(0.30)$ & 7.11 & $(0.30)$ \\
\hline Test for difference* & 0.97 & & 0.85 & & 0.36 & & 0.83 & \\
\hline \multicolumn{9}{|l|}{ Vessel type } \\
\hline Trawler & 8.93 & $(0.32)$ & 9.00 & $(0.29)$ & 7.38 & $(0.25)$ & 7.21 & $(0.27)$ \\
\hline Danish seiners & 10.21 & $(1.16)$ & 9.43 & (1.14) & 8.45 & $(1.05)$ & 7.41 & $(0.67)$ \\
\hline Netters and liners & 9.38 & $(0.44)$ & 9.04 & $(0.43)$ & 8.04 & $(0.40)$ & 6.82 & $(0.35)$ \\
\hline Potters & 9.31 & $(0.72)$ & 9.65 & $(0.75)$ & 7.76 & $(0.68)$ & 7.60 & $(0.78)$ \\
\hline Other typeb & 9.05 & $(0.61)$ & 8.65 & $(0.51)$ & 6.73 & $0.38)$ & 7.26 & $(0.56)$ \\
\hline Test for difference* & 0.73 & & 0.82 & & 0.18 & & 0.81 & \\
\hline \multicolumn{9}{|l|}{ Days/weeks of fishing } \\
\hline 1 day & 9.50 & $(0.34)$ & 8.98 & $(0.32)$ & 7.81 & $(0.29)$ & 7.17 & $(0.29)$ \\
\hline 1-7 days & 9.02 & $(0.37)$ & 9.56 & $(0.36)$ & 7.39 & $(0.31)$ & 7.11 & $(0.28)$ \\
\hline More than 7 days & 8.72 & $(0.52)$ & 8.27 & $(0.44)$ & 7.04 & $(0.43)$ & 7.04 & $(0.58)$ \\
\hline Test for difference* & 0.42 & & 0.12 & & 0.33 & & 0.95 & \\
\hline
\end{tabular}

SD - standard deviation

Includes all other job categories: deckhands, trainees, cooks and missing's $(n=19)$

${ }^{b}$ Missings are included in other type $(n=5)$

*One way analysis of variance test statistic ( $p$-value is shown).

Table 4. Crude and multiple linear regression analysis showing the association between fatigue and physical workload in Danish commercial fishermen in 2015 using the Multidimensional Fatigue Inventory (MFI-20) $(n=261)$

\begin{tabular}{|c|c|c|c|c|c|c|c|c|}
\hline \multirow[t]{2}{*}{ Model } & \multicolumn{4}{|c|}{ Crude } & \multicolumn{4}{|c|}{ Adjusted** } \\
\hline & $\beta$ & (95\% CI) & p-value & $\mathbf{R}^{2 *}$ & $\beta$ & (95\% Cl) & p-value & Adjusted $\mathrm{R}^{2 *}$ \\
\hline General fatigue & 0.20 & $(0.13-0.27)$ & $<0.001$ & 0.11 & 0.20 & $(0.12-0.28)$ & $<0.001$ & 0.21 \\
\hline Physical fatigue & 0.11 & $(0.04-0.18)$ & 0.002 & 0.03 & 0.10 & $(0.04-0.16)$ & 0.001 & 0.20 \\
\hline Reduced activity & 0.04 & $(-0.02-0.10)$ & 0.242 & 0.01 & -0.00 & $(-0.07-0.07)$ & 0.929 & 0.16 \\
\hline Mental fatigue & 0.11 & $(0.05-0.17)$ & $<0.001$ & 0.05 & 0.09 & $(0.01-0.16)$ & 0.02 & 0.10 \\
\hline
\end{tabular}

The coefficients $(\beta)$, the confidence intervals $(95 \% \mathrm{Cl})$ and $\mathrm{p}$-values are presented.

${ }^{*} \mathrm{R}^{2}$ shows the percentage of the variance explained by the model.

**The multiple linear regression is adjusted for age, education, side line occupation, physical resources, sleep at sea, professional group - skipper vs. deckhands, type of vessel and days at sea.

dustry. Trawlers are larger in size with more automation and modern equipment compared to smaller vessel types like Danish seiners. Furthermore, more modernisation has taken place in trawlers constructed for longer voyages. Further reasons for these differences can be the extent of shiftwork and working days, and the quality of sleep conditions [12]. An explanation for the lower level of general and physical fatigue found in this study can be structural changes and mechanical assistive technology that have taken place on board fishing vessels during the last few decades. Danish fishery has benefitted from the Danish fishermen's occupational health service as well as by legal regulations of the work environment of the commercial fishing industry [9]. Consequently, the ergonomic work environment on board fishing vessels has changed considerably, and reduced the physical burdens from work. At the same time, the fishermen have improved their working patterns accordingly [9, 25]. Another explanation for the low fatigue scores may be the healthy worker effect, which refers to selection bias causing active workers to be healthier than the rest of the popula- 
tion, because those with impaired health are more likely to withdraw or be excluded from the working population [26]. Commercial fishing remains a trade with hard manual work and safety issues need to be noted. Statutory regular health examination may contribute to such selection bias [25]. Future research should address the health of fishermen who have been subject to exclusion from the fishery trade. Such analyses may illustrate the relative role of impaired health risk leading to retirement as fisherman. Another possible reason for work leave in fishermen are quotas and economy, which according to a recent study of Danish Fishermen appears to be the major reason for quitting the occupation [27].

The physical workload is significantly related to general, physical and mental fatigue but the association was weakest with mental fatigue. This suggests that physical workload primarily affects the physical experience of tiredness and fatigue, rather than mental fatigue such as suggested by former studies [11, 12]. Similar results were found in a Swedish national cross-sectional study investigating the association between workload and fatigue by a one-dimensional fatigue scale in a representative national sample of Swedish workers. This study showed that workers with high physical workload had $30 \%$ higher risk of fatigue compared to workers with low workload [28]. Our study found tight positive connection between sleep and fatigue which is in accordance with several studies of fatigue [11-15, 19, $21,28-31]$. In our analysis, we used the variable hours of sleep during fishing journeys in the multiple regression models and sleep was identified as a confounder on the association between workload and fatigue scores. None of these other studies investigated the confounding effect of sleep but rather investigated sleep as a predictor of fatigue.

The mental fatigue score in fishermen (mean: 7.6 ) is very similar to the score for the overall Danish population (mean: 7.7). Mental fatigue in fishermen may be related to the changes that have taken place during recent years such as reduced crew sizes and impaired financial options for many in the trade due to factors such as quotas and options for loans. These characteristics may contribute to increased work pressure and stress, impaired options for sleep and rest, and financial worries. In addition to high job demands and poor general health, all of these are risk factors for mental fatigue [11, 30, 31]. The mental work environment has previously received little attention although a negative development and future needs for change have been described $[25,29]$.

MFI-20 is a useful scale for measuring fatigue in the general population or population samples, even though it was originally developed for measuring patient fatigue. The absence of a gold standard for measurement of fatigue challenges comparison of results from different fatigue measurement methods based on both one- and multidimensional scales $[12,21]$. Measurement of fatigue by the application of MFI-20 is based on individual external and personal factors irrespective of presence of disease. In contrast to one-dimensional scales, the multidimensional approach of MFI-20 facilitates a characterisation of the individual person [21]. Out of the existing self-reported fatigue scales, MFI-20 represents a scale that is probably the most used in Europe [19]. Despite being based on self-reported data, the scale has been assessed as a valid scale, which does not cause information bias [20,21]. The different variation of the confounding factors on the levels of the fishermen's fatigue dimensions demonstrates the importance to apply a multidimensional scale for the assessment of the levels of fatigue and for differentiating between the causes and consequences of fatigue. Thus MFI-20 is found to be an applicable tool for assessment of fatigue levels in this sample of fishermen.

The presented findings should, however, be viewed in relation to methodological limitations. By applying a cross-sectional design, one cannot prove the causality of the association between workload and the fishermen's fatigue because the direction of the association is unclear. The low response rate of this study (28\%) can bias the estimation of the prevalence and levels of the dimensions of fatigue and the studied risk factors. However, a low response rate is commonly seen in population-based surveys of fishermen. Percin et al. [32] achieved a response rate of $20 \%$ of fishermen in the Aegean Sea, while the response rate in a study of Allen et al. [14] of British fishermen was so small that it was not feasible for calculation of response rate. However, a response rate of $65 \%$ was achieved in a previous Danish survey about injuries among fishermen [33]. The variation in response rates can be caused by multiple factors. For example, fewer questions are likely to lead to a higher response rate than surveys based on more extensive questionnaires [34]. The questionnaire applied in this study consisted of 93 questions, thus falling within the latter category. However, a recent response analysis on musculoskeletal pain based on the same sample of fishermen revealed the absence of selection bias with regard to outcome [35]. An important limitation derives from the low fatigue score when comparing fishermen with the general population. The previously discussed healthy worker effect may cause fishermen suffering from severe fatigue to leave the trade rather than fishermen who experience low fatigue. The fact that fishermen who remain in active occupation are likely to be healthier and less vulnerable with regard to fatigue may therefore be a cause for bias. This is supported by the association found in the general population between presence of disease and higher level of fatigue [26]. Future longitudinal designs may investigate causal pathways of the 
association between workload, fatigue and confounding co-variables. There are only few international guidelines for reduction and management of fatigue in the maritime industry [13], and no national guideline has been found. This shortcoming calls for future initiatives allowing for planning of targeted health promoting and preventive initiatives.

\section{CONCLUSIONS}

General fatigue was the dominant fatigue dimension among Danish fishermen but all average fatigue dimensions were lower than those of the general Danish population. We have demonstrated that the fishermen's workload was significantly associated with the level of both physical and mental fatigue, but in particular to general fatigue. It can be thus concluded that heavy physical workload is a significant risk factor for levels of fatigue dimensions. Future longitudinal studies should address the role of structural and legislative changes in fisheries for the development over time of fatigue among fishermen. Such studies can also contribute to explaining causal associations, investigating their consequences and, through better understanding, contribute further to the development and execution of effective health promotion strategies.

\section{FUNDING}

This work was supported by The European Fisheries Fund (J. no. 33010-13-k-0264).

\section{ETHICS APPROVAL AND CONSENT TO PARTICIPATE}

Informed consent was obtained from participants and this study has been approved by the Danish Data Protection Agency (J. no. 2014-41-3245).

\section{COMPETING INTEREST}

Authors declare that they have no competing interest.

\section{REFERENCES}

1. Laursen LH, Hansen HL, Jensen OC. Fatal occupational accidents in Danish fishing vessels 1989-2005. Int J Inj Contr Saf Promot. 2008; 15(2): 109-117, doi: 10.1080/17457300802240503, indexed in Pubmed: 18642168.

2. Kaerlev L, Jensen A, Hannerz H. Surveillance of hospital contacts among Danish seafarers and fishermen with focus on skin and infectious diseases-a population-based cohort study. Int J Environ Res Public Health. 2014; 11(11): 11931-11949, doi: 10.3390/ ijerph111111931, indexed in Pubmed:25411726.

3. Kaerlev L, Dahl S, Nielsen PS, et al. Hospital contacts for chronic diseases among Danish seafarers and fishermen: a population-based cohort study. Scand J Public Health. 2007; 35(5): 481-489, doi: 10.1080/14034940701267385, indexed in Pubmed: 17852993.

4. Jensen OCC, Petursdottir G, Holmen IM, et al. A review of fatal accident incidence rate trends in fishing. Int Marit Health. 2014; 65(2): 47-52, doi:10.5603/IMH.2014.0011, indexed in Pubmed: 25231324.
5. Chauvin C, Le Bouar G, Lardjane S. Analysis of occupational injuries in the sea fishing industry according to the type of fishery and the fishing activity. Int Marit Health. 2017; 68(1): 31-38, doi: 10.5603/ IMH.2017.0006, indexed in Pubmed: 28357834.

6. Roberts SE. Britain's most hazardous occupation: commercial fishing. Accid Anal Prev. 2010; 42(1): 44-49, doi: 10.1016/j. aap.2009.06.031, indexed in Pubmed: 19887143.

7. Jaremin B, Kotulak E. Mortality in the Polish small-scale fishing industry. Occup Med (Lond). 2004; 54(4): 258-260, doi: 10.1093/ occmed/kqh054, indexed in Pubmed: 15190164.

8. Roberts SE. Occupational mortality in British commercial fishing, 1976-95. Occup Environ Med. 2004; 61(1): 16-23, indexed in Pubmed: 14691268.

9. Grøn S, Rasmussen HB, Poulsen TR, Christensen FN. Safety in Danish fishing industry. Centre of Maritime Health and Society Esbjerg, 2014.

10. Törner M, Almström C, Karlsson R, et al. Working on a moving surface-a biomechanical analysis of musculo-skeletal load due to ship motions in combination with work. Ergonomics. 1994; 37(2): 345-362, doi: 10.1080/00140139408963651, indexed in Pubmed: 8119265 .

11. Jepsen JR, Zhao Z, van Leeuwen WMA. Seafarer fatigue: a review of risk factors, consequences for seafarers' health and safety and options for mitigation. Int Marit Health. 2015; 66(2): 106-117, doi: 10.5603/IMH.2015.0024, indexed in Pubmed: 26119681.

12. a Høvdanum AS, Jensen OC, Petursdóttir G, et al. A review of fatigue in fishermen: a complicated and underprioritised area of research. Int Marit Health. 2014; 65(3): 166-172, doi: 10.5603/ IMH.2014.0031, indexed in Pubmed: 25471166.

13. International Maritime Organization. Guidance on fatigue mitigation and management. International Maritim Organization London, 2001.

14. Allen $P$, Wellens $B$, Smith $A$. Fatigue in British fishermen. Int Marit Health. 2010; 62(3): 154-158, indexed in Pubmed: 21154302.

15. Gander P, van den Berg M, Signal L. Sleep and sleepiness of fishermen on rotating schedules. Chronobiol Int. 2008; 25(2): 389-398, doi:10.1080/07420520802106728, indexed in Pubmed: 18533331

16. Sąlyga J, Kušleikaitè M. Factors influencing psychoemotional strain and fatigue, and relationship of these factors with health complaints at sea among Lithuanian seafarers. Medicina (Kaunas). 2011; 47(12): 675-681, indexed in Pubmed: 22370467.

17. Østergaard H, Jepsen JR, Berg-Beckhoff G. The workload of fishermen: a cross sectional survey among Danish commercial fishermen. Int Marit Health. 2016; 67(2): 97-103, doi: 10.5603/ IMH.2016.0019, indexed in Pubmed: 27364175.

18. von Elm E, Altman DG, Egger M, et al. STROBE Initiative. The Strengthening the Reporting of Observational Studies in Epidemiology (STROBE) statement: guidelines for reporting observational studies. J Clin Epidemiol. 2008; 61(4): 344-349, doi: 10.1016/j. jclinepi.2007.11.008, indexed in Pubmed: 18313558.

19. Boter H, Mänty M, Hansen AM, et al. Self-reported fatigue and physical function in late mid-life. J Rehabil Med. 2014; 46(7): 684-690, doi:10.2340/16501977-1814, indexed in Pubmed: 24819423.

20. Smets EM, Garssen B, Bonke B, et al. The Multidimensional Fatigue Inventory (MFI) psychometric qualities of an instrument to assess fatigue. J Psychosom Res. 1995; 39(3): 315-325, doi: 10.1016/00223999(94)00125-o, indexed in Pubmed: 7636775.

21. Watt T, Groenvold M, Bjorner JB, et al. Fatigue in the Danish general population. Influence of sociodemographic factors and disease. J Epidemiol Community Health. 2000; 54(11): 827-833, doi: 10.1136/ jech.54.11.827, indexed in Pubmed: 11027196. 
22. Santos JRA. Cronbach's Alpha: A Tool for Assessing the Reliability of Scales. J Ext. 1999; 37(2).

23. Holtermann A, Jørgensen MB, Gram B, et al. Worksite interventions for preventing physical deterioration among employees in jobgroups with high physical work demands: background, design and conceptual model of FINALE. BMC Public Health. 2010; 10: 120, doi: 10.1186/1471-2458-10-120, indexed in Pubmed: 20214807.

24. Szcklo M, Nieto F. Epidemiology: Beyond the Basics. 2. edition. Jones and Bartlett Publishers, Massachusetts 2012.

25. Christiansen JM, Carlsbæk AB. Fiskere i krydspres. Centre of Maritime Health and Society Esbjerg, 2015.

26. Punnett L. Adjusting for the healthy worker selection effect in cross-sectional studies. Int J Epidemiol. 1996; 25(5): 1068-1076, doi:10.1093/ije/25.5.1068, indexed in Pubmed: 8921496.

27. Christiansen J, Carlsbæk A. Fiskerne der forsvandt. Centre of Maritime Health and Society Esbjerg, 2015.

28. Akerstedt T, Knutsson A, Westerholm P, et al. Mental fatigue, work and sleep. J Psychosom Res. 2004; 57(5): 427-433, doi:10.1016/j. jpsychores.2003.12.001, indexed in Pubmed: 15581645.

29. Hystad SW, Saus ER, Sætrevik B, et al. Fatigue in seafarers working in the offshore oil and gas re-supply industry: effects of safety climate, psychosocial work environment and shift arrangement. Int Marit Health. 2013; 64(2): 72-79, indexed in Pubmed: 23788223.
30. Ahsberg E. Dimensions of fatigue in different working populations. Scand J Psychol. 2000; 41(3): 231-241, doi: 10.1111/14679450.00192, indexed in Pubmed: 11041305.

31. Akerstedt T, Fredlund P, Gillberg M, et al. Work load and work hours in relation to disturbed sleep and fatigue in a large representative sample. J Psychosom Res. 2002; 53(1): 585-588, doi: 10.1016/ s0022-3999(02)00447-6, indexed in Pubmed: 12127175.

32. Percin F, Akyol O, Davas A, et al. Occupational health of Turkish Aegean small-scale fishermen. Occup Med (Lond). 2012; 62(2): 148-151, doi:10.1093/occmed/kqr181, indexed in Pubmed: 22113895.

33. Jensen OC. Work related injuries in Danish fishermen. Occup Med (Lond). 1996; 46(6): 414-420, doi: 10.1093/occmed/46.6.414, indexed in Pubmed:8987374.

34. Deutskens E, Ruyter Kode, Wetzels M, et al. Response Rate and Response Quality of Internet-Based Surveys: An Experimental Study. Mark Lett. 2004; 15(1): 21-36, doi: 10.1023/b:ma rk.0000021968.86465.00.

35. Berg-Beckhoff G, Østergaard H, Jepsen JR. Prevalence and predictors of musculoskeletal pain among Danish fishermen - results from a cross-sectional survey. J Occup Med Toxicol. 2016; 11: 51, doi: 10.1186/s12995-016-0140-7, indexed in Pubmed: 27891170. 